\title{
Patient blood management: Need of the hour
}

\author{
Sadhana Mangwana
}

Blood and blood products are the most precious resources to any healthcare institution. Judicious use of these limited resources is necessary and significant to preserve adequate supply [1]. Blood and blood components transfusion play a vital role in clinical care. Blood transfusion can be lifesaving but despite advances in safety of blood supply, allogenic blood transfusions carry inherent risks and are associated with poor patient outcomes including bacterial infections, transfusion transmitted infections, increased length of stay, prolonged morbidity and mortality. Avoiding or minimizing transfusion leads to fewer donor exposures, fewer transfusion reactions and lowering treatment cost. Patient blood management (PBM) is an evidenced-based, multidisciplinary approach to optimize patient's care that might need transfusion. The goal of patient blood management is to introduce strategies to prevent patients from needing a transfusion and to improve outcomes by blood transfusions. Patient blood management encompasses all aspects of patient evaluation and clinical management surrounding the transfusion decisionmaking process including optimization of patient red blood cell volume, application of appropriate indications and minimizing blood loss [2].

Several organizations have focused on patient blood management and various national bodies like AABB and The Society for the Advancement for Blood Management (SABM) have drafted patient blood management guidelines and Patient Blood Management program standards [3]. AABB standards for patient blood management has designated patient blood management program as an activity level 1, 2, or 3 while The Society

\section{Sadhana Mangwana}

Affiliation: M.D., MBA (HCS), Academic Position in the Department, Sr. Consultant and Head, Department of Transfusion Medicine and Immunohematology, Sri Balaji Action Medical Institute, Paschim Vihar, New Delhi, India.

Corresponding Author: Dr. Sadhana Mangwana, G- 17, Pocket-2, Naraina Vihar, New Delhi-110028, India; Email: sadhanamangwana@yahoo.co.in

Received: 23 December 2017

Published: 18 January 2018 for Advancements of Blood Management offers administrative and clinical standards for patient blood management outlining 12 standards related to activities of formal, comprehensive and organization-wise patient blood management program $[4,5]$. An effective patient blood management program has multiple approaches spanning from prehospitalization through hospitalization and till after discharge. Elements of comprehensive patient blood management program include:

- Evidenced based guidelines for transfusion indications and dose.

- $\quad$ Physician education and monitoring.

- Preoperative anemia evaluation and management.

- Intraoperative and postoperative autologous salvage.

- Intraoperative normovolemic hemodilution.

- Point-of-care hemostatic testing.

- Use of hemostatic agents.

- Limiting phlebotomy blood loss.

Adoption of transfusion guidelines across the clinical services of hospital drafted by multidisciplinary committee is a key component of a patient blood management program. Transfusion guidelines should address indication for each component along with recommended doses. Guidelines should be implemented with various audits like blood utilization review, internal and external benchmarking, patient mobility and mortality data, transfusion administration compliance, transfusion reaction rates, etc. Blood utilization is a peerreview activity. Blood utilization review program educates clinicians for appropriate transfusion, review local transfusion practice and provide feedback on transfusion trends [6]. Elements for review include ordering patterns, appropriateness of blood use, blood administration policies and completeness of documentation for transfusion. Transfusion data is aggregated and analyzed for trending and identification of outliers and/or monitor individual transfusions in real-time.

Physician education is another important and integral foundation for effective patient blood management program success since many physicians ordering blood may not be familiar with indications for transfusions or with alternative treatments. The best way to reduce aberrant transfusion practice is through multimodal 
approach involving informal discussions, automated alerts using various softwares, and by providing data and latest research studies [3]. Physicians should be educated about transfusion thresholds, waste reduction strategies and techniques to avoid transfusion. Education activities for physician and non-physician clinical staff about transfusion thresholds, waste-reduction strategies and techniques to avoid transfusion can bring the most optimum effects of patient blood management [7].

Patient blood management program can be developed to manage preoperative anemia by identifying patients 4 weeks prior to surgery and who are expected to feature significant blood loss during surgery. These patients can be evaluated and managed by appropriate management strategies like oral iron, intravenous iron, folic acid, vitamin B12 and/ or erythropoietin (EPO).

During the operative period, members of health care team should be vigilant for noticing signs and symptoms of blood loss. Anticipation, rapid diagnosis and control of hemorrhage should be undertaken as early as possible before the patient loses physiologic reserve. Blood that is shed from wound or drainage can be recovered/salvaged and reinfused.

Minimizing phlebotomy blood loss for laboratory testing and point of care testing would help in taking quick decisions and managing patients efficiently especially with coagulopathic bleeding and blood product therapy.

Benefits of transfusion should be weighed against unexpected risks and worse outcomes. From patient's perspective, patient blood management is able to make informed choice, access to higher quality of care and less risk. An understanding of all the contributor factors to the cost of transfusion is important for hospitals to develop and reducing unnecessary transfusions and improving blood utilization. According to a study in Germany, predicted shortfall in the blood supply could be $47 \%$ by 2020 [8]. The Institute of Medicine estimated in 2009 that $30 \%$ health care spending was wasteful and unnecessary and blood transfusion was identified by American Medical Association and The Joint Commission (TJC) as one of the top-five most frequently overused therapies [9]. Goodnough et al. [10, 11] estimated annual net savings of $\$ 1.6$ million by using restrictive transfusion strategy and accumulated net savings of $\$ 6.4$ million over the four-year period from 2010 to 2013 and likely far greater impact on total transfusion-related costs.

In the era of quality consciousness and to curtail inappropriate and potentially injurious transfusion practices, various national and international accreditation agencies like AABB and TJC are promoting initiatives in patient blood management. Patient blood management would help in compliances, implementing corrective actions and process improvements.

With increasing awareness and demand of cost reduction to increasing healthcare cost, decrease reimbursements and pressure to reduce investigations and procedures, optimizing the blood usage by patient blood management is an important tool. With all these initiatives, community would be benefitted by supporting safe and adequate supply to the needy. Improvements in transfusion practices by evidence-based, transfusion guidelines and blood utilization reviews can be brought by employment of transfusion safety officer or patient blood management coordinators who would provide regular education to all staff involved in transfusion practice, increased awareness of transfusion alternatives, promote optimal transfusions. A patient blood management program is one of the most powerful ways to optimize patient care in a cost-effective manner.

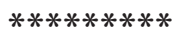

Keywords: Patient blood management, Transfusion, Blood utilization

\section{How to cite this article}

Mangwana S. Patient blood management: Need of the hour. Int $\mathrm{J}$ Blood Transfus Immunohematol 2018;8:1-3.

Article ID: 100035IJBTISM2018

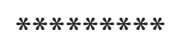

doi: 10.5348/ijbti-2018-35-ED-1

\section{REFERENCES}

1. Mangwana S, Bedi N, Yadav P, Chugh R. Optimization of blood transfusion services: Analysis of blood requisition and utilization practices in cardiac surgical patients in a tertiary care hospital, India. Glob J Transfus Med AATM 2017;2:47-51.

2. AABB. Building a better patient blood management program: An AABB whitepaper. Bethesda, MD. 2015. [Available at: http://www.aabb.org/pbm/ Documents/AABB-PBM-Whitepaper.pdf]

3. Triulzi DJ, Yazer MH, Waters JH. Patient blood management. In: Simon TL, McCullough J, Snyder EL, Solheim BJ, Stauss RG, editors. Rossi's Principles of Transfusion Medicine. 5ed. UK: Wiley Blackwell; 2016. p. 13-22.

4. Holcomb J. Standards for a patient blood management program. Bethesda, MD: AABB; 2014.

5. Freedman J, Luke K, Escobar M, Vernich L, Chiavetta JA. Experience of a network of transfusion coordinators for blood conservation (Ontario Transfusion Coordinators [ONTraC]). Transfusion 2008 Feb;48(2):237-50. 
6. Savage W. Implementing a blood utilization program to optimize transfusion practice. Hematology Am Soc Hematol Educ Program 2015;2015:444-7.

7. Karafin MS, Bryant BJ. Transfusion medicine education: An integral foundation of effective blood management. Transfusion 2014 May;54(5):1208-11.

8. Greinacher A, Fendrich K, Brzenska R, Kiefel V, Hoffmann W. Implications of demographics on future blood supply: A population-based cross-sectional study. Transfusion 2011 Apr;51(4):702-9.

9. Morton J, Anastassopoulos KP, Patel ST, et al. Frequency and outcomes of blood products transfusion across procedures and clinical conditions warranting inpatient care: An analysis of the 2004 healthcare cost and utilization project nationwide inpatient sample database. Am J Med Qual 2010 JulAug;25(4):289-96.

10. Goodnough LT, Shieh L, Hadhazy E, Cheng N, Khari P, Maggio P. Improved blood utilization using realtime clinical decision support. Transfusion 2014 May;54(5):1358-65.

11. Goodnough LT, Maggio P, Hadhazy E, et al. Restrictive blood transfusion practices are associated with improved patient outcomes. Transfusion 2014 Oct;54(10 Pt 2):2753-9.

\section{SUGGESTED READING}

- $\quad$ Ghiglione M, Puca KE. Patient blood management. In: Roback JD, Grossman BJ, Harris T, Hillyer CD, editors. Technical Manual. 18ed. AABB; 2014. p. 599619.

- $\quad$ The Society for the Advancement of Blood (SABM). The administrative and clinical standards for patient blood management programs. 2ed. Englewood, NJ: SABM; 2013.

$$
* * * * * * * * *
$$

\section{Author Contributions}

Sadhana Mangwana - Substantial contributions to conception and design, Acquisition of data, Analysis and interpretation of data, Drafting the article, Revising it critically for important intellectual content, Final approval of the version to be published

\section{Guarantor of Submission}

The corresponding author is the guarantor of submission.

\section{Source of Support}

None

\section{Conflict of Interest}

Author declares no conflict of interest.

\section{Copyright}

(C) 2018 Sadhana Mangwana. This article is distributed under the terms of Creative Commons Attribution License which permits unrestricted use, distribution and reproduction in any medium provided the original author(s) and original publisher are properly credited. Please see the copyright policy on the journal website for more information.
Access full text article on other devices

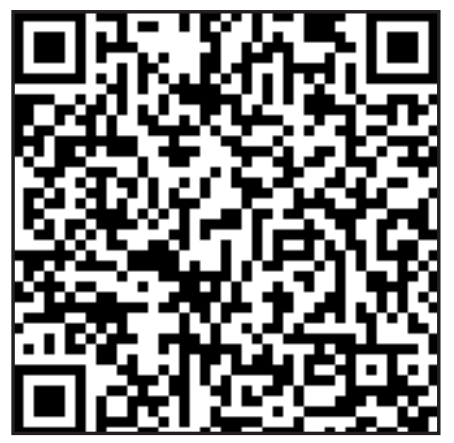

Access PDF of article on other devices

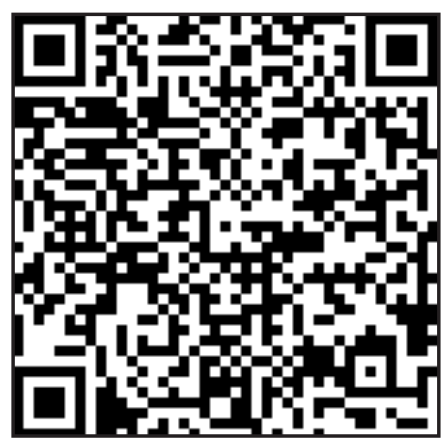

